\title{
Bioequivalence Evaluation of Two Esomeprazole 20 mg Capsule Formulations in Healthy Male Bangladeshi Volunteers
}

\author{
Mohammad Safiqul Islam ${ }^{1}$, Nahia Akter ${ }^{1}$, Hasanuzzaman Shohag ${ }^{1}$, Ashik Ullah ${ }^{1}$, Abdullah Al Maruf ${ }^{1}$, Tasmin Ara Sultana ${ }^{1}$, A. H. M. Mahbub \\ Latif $^{2}$ and Abul Hasnat ${ }^{1 *}$
}

${ }^{1}$ Department of Clinical Pharmacy and Pharmacology, Faculty of Pharmacy, University of Dhaka, Dhaka-1000, Bangladesh

${ }^{2}$ Institute of Statistical Research and Training, University of Dhaka, Dhaka-1000, Bangladesh

\begin{abstract}
Bioequivalence study of two esomeprazole $20 \mathrm{mg}$ capsule formulations namely Esolok ${ }^{\circledR} 20$ (Test product) and Nexium20 (Reference product) was carried out in the present study. 24 healthy male volunteers were enrolled into this randomized, single-dose, two-period, crossover, open-label pharmacokinetic study with one week washout period. After administering a single dose of $20 \mathrm{mg}$ of each formulation, blood samples were collected at different time intervals and analyzed for esomeprazole concentrations using a validated HPLC method. Non-compartmental method was used to determine different pharmacokinetic parameters. Obtained mean (SD) values for the test and reference products were $1.45(0.53)$ and $1.53(0.47) \mu \mathrm{g} / \mathrm{ml}$ for $\mathrm{C}_{20 x} ; 2.25(0.57)$ and $2.21(0.71) \mathrm{hr}$ for $\mathrm{T}_{\text {max }} ; 4.38(2.04)$ and 4.37 (2.35) $\mathrm{hr}-\mu \mathrm{g} / \mathrm{ml}$ for $\mathrm{AUC}_{0-12}$; and 4.59 (1.99) and 4.62 (2.39) $\mathrm{hr}-\mu \mathrm{g} / \mathrm{ml}$ for $\mathrm{AUC}_{0-\infty}$, respectively. The $90 \%$ $\mathrm{Cls}$ of the test/reference mean ratios of the In-transformed $\mathrm{AUC}, \mathrm{AUC}$ and $\mathrm{C}$ mean values were $102.51 \%$ (88.10\% - 119.27\%), 101.92\% (87.32\% - 118.96\%) and 92.56\% (85.73\% - 99.93\%) respectively, which were within the predetermined FDA bioequivalence range of $80 \%-125 \%$. In conclusion, the test and reference formulations of esomeprazole meet the regulatory criteria for bioequivalence both in terms of rate and extent of absorption.
\end{abstract}

Keywords: Esomeprazole; Proton pump inhibitors; Bioequivalence; Pharmacokinetics; Bangladeshi volunteers

\section{Introduction}

Esomeprazole, the S-isomer of omeprazole was developed with the aim of improving the pharmacokinetic and pharmacodynamic profiles of racemic omeprazole [1]. It suppresses the secretion of hydrochloric acid from gastric parietal cells via inhibition of the $\mathrm{H}+/ \mathrm{K}+$ adenosine triphosphatase enzyme like other proton pump inhibitors [2]. Among all proton pump inhibitors available, esomeprazole is the first to demonstrate significantly greater healing rates than omeprazole in the treatment of patients with erosive oesophagitis [3,4].

Esomeprazole is absorbed rapidly after oral administration [5]. The peak serum concentration of esomeprazole $\left(\mathrm{C}_{\max }\right)$ was found to be within 0.5 hours of ingestion of an oral solution containing $20 \mathrm{mg}$ and within 1 to 3.5 hours for encapsulated enteric-coated granules (40 $\mathrm{mg}$ ) in two studies in a total of 32 healthy volunteers [5]. Increases in systemic exposure, as shown by areas under the plasma-concentration time curves (AUCs), are dose-related after single doses, increasing in a nonlinear fashion [6]. Esomeprazole is metabolized extensively in the liver by two cytochrome P450 isoenzymes to metabolites devoid of antisecretory activity [6,7]. The drug is primarily metabolized by CYP2C19 to hydroxyl and desmethyl metabolites and to a lesser degree by CYP3A4 to sulfone metabolites [8].

The use of generic drugs has increased due to their effectiveness and the increasing variety of drugs that are now available as generic formulations in the recent years. However, their use in clinical practice depends not only on their essential similarity (in formulation and composition, as determined by regulatory agencies), but also on their bioequivalence with their reference counterparts. Therefore, study of the comparative bioavailability of test and reference formulations is important for appropriate assessment by the scientific community [9]. Two drugs are considered to be bioequivalent if they are pharmaceutically equivalent and their bioavailability is so similar that they are unlikely to produce clinically relevant differences in regard to safety and efficacy $[9,10]$.
The aim of this study was to investigate the pharmacokinetic profiles of two $20 \mathrm{mg}$ esomeprazole formulations, namely Esolok ${ }^{\circledR} 20$ (Test product; Batch no: 38; Mfg. Date: Apr 2010; Exp. Date: Apr 2012) manufactured by The Ibn Sina Pharmaceutical Industry Ltd., Bangladesh and Nexium ${ }^{\circledR} 20$ (Reference product; Batch no: v1851; Exp. Date: 01-2012) manufactured by AstraZeneca, Wilmington, Delaware, US in healthy adult male Bangladeshi volunteers.

\section{Materials and Method}

\section{Subjects}

A total of 24 healthy subjects were enrolled into the study to achieve $80 \%$ power with $90 \%$ confidence interval [11] with mean (SD) age, 20.75 (0.965) years (range 19 - 22 years); mean (SD) body weight, 68.43 (9.7) kg (range 50 - $86 \mathrm{~kg}$ ); mean (SD) height, 1.73 (0.07) $\mathrm{m}$ (range 1.60 $-1.81 \mathrm{~m})$ and mean (SD) body mass index (BMI), $22.77(2.22) \mathrm{kg} / \mathrm{m}^{2}$ (range $18.86-26.84 \mathrm{~kg} / \mathrm{m}^{2}$ ).

All subjects were examined to verify their health status; these examinations included medical history, vital sign measurements, electrocardiography (ECG), blood sample analysis (basic profile, complete blood cell count, bleeding time, clotting time, prothrombin time, viral serology), and urinalysis (sediment, drugs). Subjects with

${ }^{*}$ Corresponding author: Dr. Abul Hasnat, Professor, Department of Clinica Pharmacy and Pharmacology, Faculty of Pharmacy, University of Dhaka, Dhaka - 1000, Bangladesh, Tel: +880-2-9667850; Fax: +880-2-8615583; E-mail: ahasnat99@yahoo.com

Received October 09, 2010; Accepted March 28, 2011; Published August 03, 2011

Citation: Islam MS, Akter N, Shohag H, Ullah A, Al Maruf A, et al. (2011) Bioequivalence Evaluation of Two Esomeprazole $20 \mathrm{mg}$ Capsule Formulations in Healthy Male Bangladeshi Volunteers. J Bioequiv Availab 3: 139-143. doi:10.4172/ jbb.1000074

Copyright: ( 2011 Islam MS, et al. This is an open-access article distributed under the terms of the Creative Commons Attribution License, which permits unrestricted use, distribution, and reproduction in any medium, provided the original author and source are credited. 
relevant clinical, analytical, or ECG abnormalities were excluded from the trial. Additional exclusion criteria were as follows: smoking; history of alcohol or other drug abuse; consumption of any medication within one month prior to study commencement, participation in a clinical trial in the 4 months before enrollment; history of clinically important illness or major surgery in the 6 months before enrollment; inability to relate to and/or cooperate with the investigators; medication allergy; illnesses or disorders that could affect the absorption, distribution, metabolism, and/or excretion of drugs (e.g. malabsorption, edemas, renal and/or hepatic failure); a history of positive serology for hepatitis $\mathrm{B}$ or $\mathrm{C}$ (not due to immunization) or HIV; blood loss or donation in the 3 months before enrollment; blood or blood-derivative transfusion in the 6 months before enrollment; and exhausting physical exercise in the 72 hours before enrollment.

\section{Study design}

Ethical permission and the protocol for the study was reviewed and approved by Bangladesh Medical Research Council (BMRC) (BMRC/ NREC/2010-2013/623). The study was conducted in the Department of Clinical Pharmacy and Pharmacology, Faculty of Pharmacy, University of Dhaka, Bangladseh in association with a well-equipped private clinic in Dhaka. The study was conducted in accordance with the International Conference of Harmonization (ICH) guideline for Good Clinical Practice (GCP) and in compliance with the Declaration of Helsinki and its further amendments [12,13]. All eligible subjects provided written informed consent to participate and were free to withdraw from the study at any time without any obligation.

The study was a single-dose, randomized, open-label, twoperiod crossover design with a one week washout period. A single 20 -mg capsule of either formulation (Esolok ${ }^{\circledR} 20$ or Nexium ${ }^{\circledR} 20$ ) was administered with $250 \mathrm{ml}$ of water after an overnight fast. A standardized breakfast and lunch were given at 4 and 8 hours after drug administration. The consumption of alcohol, grapefruit juice, and beverages was not permitted for 72-hr prior to the study, or after drug administration, until final blood samples were collected. Food intake was strictly controlled and all volunteers received the same food to minimize the effects of food on the study outcomes. During the study period, the volunteers were under medical surveillance by two registered physicians to report any adverse events at all times.

\section{Tolerability}

Tolerability was determined by monitoring blood pressure, heart rate, body temperature at the start of the study, 4 hourly during the study, and at the end of each period. A full physical examination was also performed before and 24 hours after drug administration. Laboratory results (hematology, urinalysis, blood biochemistry) were collected before and after the study for all the subjects. The participants were interviewed by the physicians using a structured questionnaire and data collection system as well as nonspecific questioning. All the subjects were advised to report any adverse events at any time during the study period.

\section{Blood sampling}

A $20-G \times 1.25$-inch catheter Vasofix $^{\circledR}$ Braunüle $^{\circledR}$, B.Braun Melsungen AG, Melsungen, Germany) was inserted into a suitable forearm vein and $3 \mathrm{ml}$ of blood was withdrawn during each time of collection. Venous blood samples were obtained prior to dosing 0 (baseline) and at 0.5. 0.75, 1.0, 1.25, 1.5, 1.75, 2.0, 2.5, 3.0, 3.5, 4.0, 5.0, 7.0, 9.0, and $12.0 \mathrm{~h}$ after dosing. The blood samples were kept for 30 minutes at ambient temperature in a dark place and then centrifuged at $3000 \mathrm{rpm}$ for 15 minutes at $25^{\circ} \mathrm{C}$. Collected serum was stored at $-80^{\circ} \mathrm{C}$ until further analysis. Protective measures were taken against light during sample collection and analysis as esomeprazole is a light sensitive drug.

\section{Chromatographic analysis}

Esomeprazole and pantoprazole (internal standard) were extracted from human serum samples by protein precipitation method using methanol [14]. After protein precipitation, the supernatant was collected. $20 \mu \mathrm{l}$ of the sample was injected into the chromatographic system.

Esomeprazole and pantoprazole were determined in serum samples according to the method of [15] with slight modifications. Briefly, esomeprazole and pantoprazole (internal standard) were analyzed on a Shimadzu (Kyoto, Japan) HPLC system, which consists of a SCL-10Avp system controller, two LC-8A pumps. The data were acquired and processed using LC solution (Version 1.03 SP3, Shimadzu Corporation, Kyoto, Japan) software running under Windows XP on a Pentium PC. Ultraviolet detection was achieved with a SPD-10Avp UV-VIS detector (Shimadzu Corporation; Kyoto, Japan) at $302 \mathrm{~nm}$ at a sensitivity of 0.0001 AUFS. The mobile phase consisted of $5 \mathrm{mM}$ potassium dihydrogen phosphate buffer ( $\mathrm{pH} 7.2 \pm 0.05$ adjusted with $10 \%$ solution of potassium hydroxide) and acetonitrile (70:30) passed through XTerra C8 column $(5 \mu, 4.6 \times 250 \mathrm{~mm}$, Waters, Massachusetts, USA) at room temperature at a flow rate of $1.0 \mathrm{ml} / \mathrm{min}$.

Quantification of esomeprazole in serum samples was obtained by plotting esomeprazole to internal standard peak area ratio as a function of esomeprazole concentration. The method of analysis was validated under the principles of Good Laboratory Practice through the following parameters: linearity, precision, accuracy, limit of quantification (LOQ), specificity, stability, and recovery $[10,16]$. Both esomeprazole and pantoprazole solutions were prepared in mobile phase to make a concentration of $10 \mu \mathrm{g} / \mathrm{mL}$ each. The pantoprazole was further diluted to prepare a concentration of $1 \mu \mathrm{g} / \mathrm{mL}$. The calibration standards were prepared by adding required amount of the esomeprazole stock solution, $100 \mu \mathrm{l}$ of protein precipitated blank serum and $100 \mu \mathrm{l}$ of internal standard solution $(1 \mu \mathrm{g} / \mathrm{ml}$ of pantoprazole $)$ to the diluent to achieve the esomeprazole concentrations of $2.0,1.0,0.5,0.2,0.1,0.05$ and $0.02 \mu \mathrm{g} / \mathrm{ml}$. These samples were analyzed by the above mentioned HPLC method for the construction of calibration curves and method validation. A series of quality control samples were prepared by spiking treated blank serum with required amount of esomeprazole and pantoprazole (internal standard) to yield the final serum samples of $0.02,0.2,2.0 \mu \mathrm{g} / \mathrm{ml}$ of esomeprazole and were run in HPLC after every 10 analytical run to verify its performance. All the standards solutions were kept at $-80^{\circ} \mathrm{C}$ until further analysis.

\section{Pharmacokinetic and statistical analysis}

Pharmacokinetic properties were calculated by a noncompartmental approach from serum concentrations of esomeprazole using software Kinetica (Version 4.4.1, Thermo Electron Corporation, $\mathrm{UK}) . \mathrm{C}_{\max }$ was estimated directly from observed concentrations, and $\mathrm{T}_{\max }$ as the corresponding time point at which $\mathrm{C}_{\max }$ occurred. $\mathrm{AUC}_{0-\mathrm{t}}$ was calculated by the linear trapezoidal method until the last measurable serum drug concentration, and $\mathrm{AUC}_{0-\infty}$ was calculated as $\mathrm{AUC}_{0-\infty}=\mathrm{AUC}_{0-\mathrm{t}}+\mathrm{C}_{\text {last }} / \mathrm{K}_{\mathrm{el}} \cdot \mathrm{k}_{\mathrm{el}}$ was the terminal elimination rate constant calculated by linear least square regression of the last three to four time points in the log concentration time profile and the terminal half-life was calculated by the following equation [14] : $\mathrm{t}_{1 / 2}=0.693 / k_{e l}$. The mean residence time (MRT) was calculated as: 
Citation: Islam MS, Akter N, Shohag H, Ullah A, Al Maruf A, et al. (2011) Bioequivalence Evaluation of Two Esomeprazole 20 mg Capsule Formulations in Healthy Male Bangladeshi Volunteers. J Bioequiv Availab 3: 139-143. doi:10.4172/jbb.1000074

\begin{tabular}{|c|c|c|c|c|c|c|c|}
\hline \multicolumn{8}{|c|}{ Test Formulation $(n=24)$} \\
\hline Pharmacokinetic parameters & Mean & Median & Geometric Mean & SD & CV (\%) & Max & Min \\
\hline $\mathrm{C}_{\max }(\mu \mathrm{g} / \mathrm{ml})$ & 1.45 & 1.46 & 1.35 & 0.53 & 36.58 & 2.28 & 0.67 \\
\hline $\mathrm{T}_{\max }(\mathrm{hr})$ & 2.25 & 2.50 & 2.17 & 0.57 & 25.51 & 3.00 & 1.00 \\
\hline $\mathrm{AUC}_{0-12}(\mathrm{hr}-\mu \mathrm{g} / \mathrm{ml})$ & 4.38 & 4.42 & 3.96 & 2.04 & 46.44 & 8.21 & 2.08 \\
\hline $\mathrm{AUC}_{0-\infty}(\mathrm{hr}-\mu \mathrm{g} / \mathrm{ml})$ & 4.59 & 4.69 & 4.19 & 1.99 & 43.31 & 8.23 & 2.15 \\
\hline $\mathrm{k}_{\mathrm{el}}\left(\mathrm{hr}^{-1}\right)$ & 0.35 & 0.37 & 0.33 & 0.11 & 30.83 & 0.47 & 0.16 \\
\hline $\mathrm{AUMC}_{0-12}\left(\mathrm{hr}^{2}-\mu \mathrm{g} / \mathrm{ml}\right)$ & 18.65 & 19.71 & 16.54 & 8.96 & 48.03 & 35.65 & 6.03 \\
\hline $\mathrm{AUMC}_{0-\infty}\left(\mathrm{hr}^{2}-\mu \mathrm{g} / \mathrm{ml}\right)$ & 21.93 & 21.39 & 19.81 & 8.92 & 40.68 & 35.93 & 6.78 \\
\hline $\mathrm{t}_{1 / 2}(\mathrm{hr})$ & 2.24 & 1.85 & 2.10 & 0.93 & 41.55 & 4.20 & 1.47 \\
\hline MRT (hr) & 4.86 & 4.49 & 4.73 & 1.22 & 25.20 & 7.49 & 3.16 \\
\hline \multicolumn{8}{|c|}{ Reference Formulation $(n=24)$} \\
\hline Pharmacokinetic parameters & Mean & Median & Geometric Mean & SD & CV (\%) & Max & Min \\
\hline $\mathrm{C}_{\max }(\mu \mathrm{g} / \mathrm{ml})$ & 1.53 & 1.57 & 1.46 & 0.47 & 30.74 & 2.23 & 0.80 \\
\hline $\mathrm{T}_{\max }(\mathrm{hr})$ & 2.21 & 2.00 & 2.10 & 0.71 & 31.96 & 3.50 & 1.00 \\
\hline $\mathrm{AUC}_{0-12}(\mathrm{hr}-\mu \mathrm{g} / \mathrm{ml})$ & 4.37 & 3.50 & 3.86 & 2.35 & 53.78 & 9.47 & 1.90 \\
\hline $\mathrm{AUC}_{0-\infty}(\mathrm{hr}-\mu \mathrm{g} / \mathrm{ml})$ & 4.62 & 3.56 & 4.11 & 2.39 & 51.77 & 9.48 & 2.00 \\
\hline $\mathrm{k}_{\mathrm{el}}\left(\mathrm{hr}^{-1}\right)$ & 0.39 & 0.36 & 0.35 & 0.18 & 45.94 & 0.77 & 0.17 \\
\hline $\mathrm{AUMC}_{0-12}\left(\mathrm{hr}^{2}-\mu \mathrm{g} / \mathrm{ml}\right)$ & 18.05 & 12.40 & 15.21 & 11.34 & 62.83 & 39.69 & 5.86 \\
\hline $\mathrm{AUMC}_{0-\infty}\left(\mathrm{hr}^{2}-\mu \mathrm{g} / \mathrm{ml}\right)$ & 22.05 & 15.87 & 18.73 & 12.91 & 58.53 & 41.69 & 7.31 \\
\hline $\mathrm{t}_{1 / 2}(\mathrm{hr})$ & 2.16 & 1.95 & 1.96 & 0.97 & 45.18 & 4.12 & 0.90 \\
\hline MRT (hr) & 4.69 & 4.43 & 4.56 & 1.25 & 26.56 & 7.42 & 3.47 \\
\hline
\end{tabular}

Table 1: Serum pharmacokinetic parameters of all the volunteers for test and reference formulations.

$$
\mathrm{MRT}=\frac{A U M C_{0-\infty}}{A U C_{0-\infty}}
$$

The parameters were tested for difference by paired $t$-test at $5 \%$ level of significance. Analysis of variance (ANOVA) was carried out to evaluate the source of variations. The ANOVA model included sequence, subject nested within sequence, phase and treatment (test and reference) as factors [17]. Large sample based $90 \%$ Confidence Interval for pharmacokinetic parameters such as $\mathrm{C}_{\max }, \mathrm{AUC}_{0-\mathrm{t}}$ and $\mathrm{AUC}_{0-\infty}$ were analyzed for the assessment of bioequivalence after logarithmic transformation according to the current FDA guidelines [10].

\section{Results}

\section{Method validation}

The analytical method was specific, sensitive, accurate and precise. The chromatograms showed that both the peaks were completely resolved from one another and also from serum components (Figure

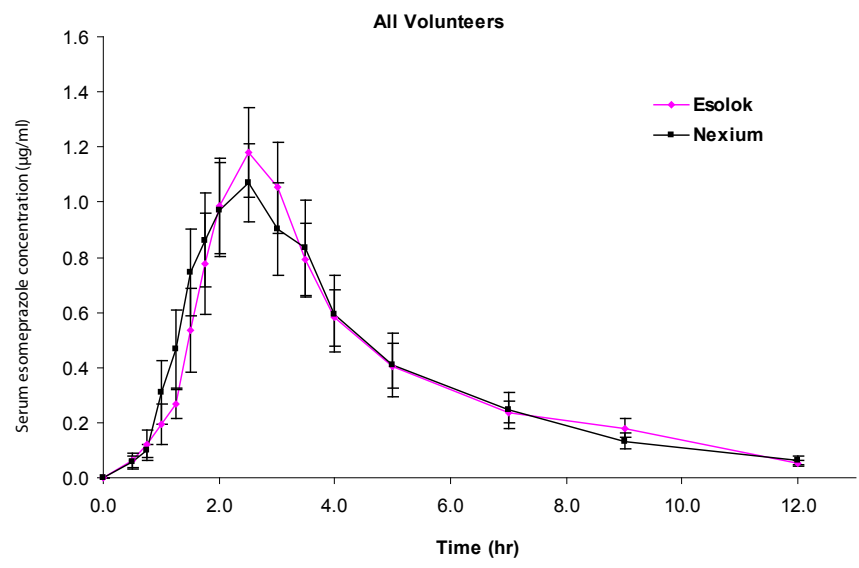

Figure 1: Mean (SEM) esomeprazole concentration-versus-time curve over 12 hours in adult healthy Bangladeshi male volunteers $(N=24)$.

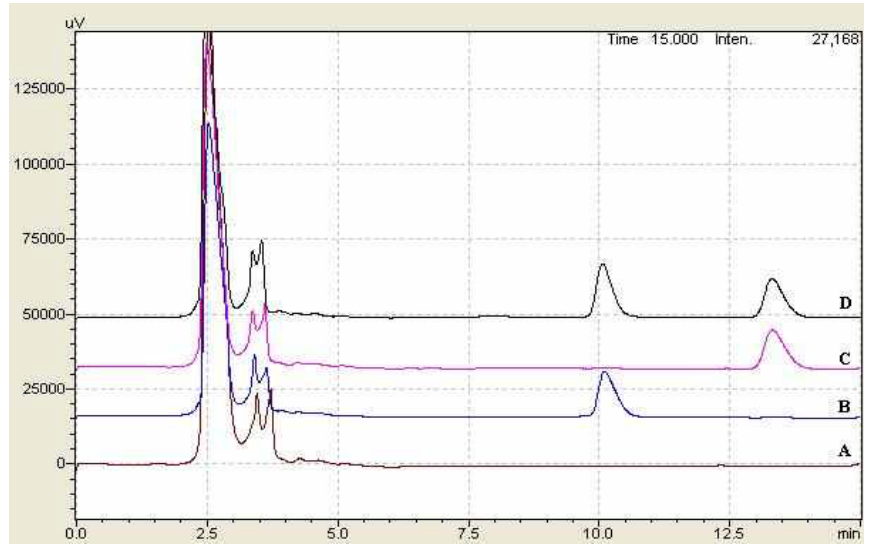

Figure 2: Representative chromatograms obtained from A) drug-free serum sample B) serum spiked with esomeprazole $C$ ) serum spiked with internal standard (pantoprazole) D) extracted serum sample from a volunteer $2.0 \mathrm{~h}$ after a $20 \mathrm{mg}$ oral dose of esomeprazole.

\begin{tabular}{|l|c|}
\hline Parameters & $p$-value \\
\hline $\mathrm{C}_{\max }(\mu \mathrm{g} / \mathrm{ml})$ & 0.198 \\
\hline $\mathrm{T}_{\max }(\mathrm{hr})$ & 0.878 \\
\hline $\mathrm{AUC}_{0-12}(\mathrm{hr}-\mu \mathrm{g} / \mathrm{ml})$ & 0.974 \\
\hline $\mathrm{AUC}_{0-\infty}(\mathrm{hr}-\mu \mathrm{g} / \mathrm{ml})$ & 0.943 \\
\hline $\mathrm{k}_{\mathrm{el}}\left(\mathrm{hr}^{-1}\right)$ & 0.471 \\
\hline $\mathrm{AUMC}_{0-12}\left(\mathrm{hr}^{2}-\mu \mathrm{g} / \mathrm{ml}\right)$ & 0.797 \\
\hline $\mathrm{AUMC}_{0-\infty}\left(\mathrm{hr}^{2}-\mu \mathrm{g} / \mathrm{ml}\right)$ & 0.968 \\
\hline $\mathrm{t}_{1 / 2}(\mathrm{hr})$ & 0.809 \\
\hline $\mathrm{MRT}(\mathrm{hr})$ & 0.710 \\
\hline
\end{tabular}

Table 2: $\mathrm{P}$ values of paired $t$-test.

2). No interferences were seen in any individual study subject's baseline of drug-free serum. The calibration curve was found to be linear over the concentration range of 0.02 to $2.0 \mu \mathrm{g} / \mathrm{ml}$ with regression coefficient of 0.9996 . The limit of quantification was found as the 


\begin{tabular}{|c|c|c|c|c|c|c|c|c|c|}
\hline Sources of Variations & $\underset{(\mu \mathrm{g} / \mathrm{ml})}{\mathrm{C}_{\max }}$ & $\begin{array}{l}\mathrm{T}_{\max } \\
(\mathrm{hr})\end{array}$ & $\begin{array}{c}A^{A U C_{0-12}}(\mathrm{hr}-\mu \mathrm{g} / \\
\mathrm{ml})\end{array}$ & $\begin{array}{c}A^{A U C_{0-\infty}(h r-\mu g /} \\
m l)\end{array}$ & $\begin{array}{c}\mathrm{K}_{\mathrm{el}} \\
\left(\mathrm{hr}^{-1}\right)\end{array}$ & $\begin{array}{l}t_{1 / 2} \\
(h r)\end{array}$ & $\begin{array}{l}\text { AUMC }_{0-12} \\
\left(\mathrm{hr}^{2}-\mu \mathrm{g} / \mathrm{ml}\right)\end{array}$ & $\begin{array}{c}\text { AUMC }_{0-\infty} \\
\left(\mathrm{hr}^{2}-\mu \mathrm{g} / \mathrm{ml}\right)\end{array}$ & $\begin{array}{c}\text { MRT } \\
\text { (hr) }\end{array}$ \\
\hline Formulation & 0.111 & 0.829 & 0.781 & 0.829 & 0.644 & 0.660 & 0.506 & 0.721 & 0.674 \\
\hline Period & 0.641 & 0.510 & 0.971 & 0.944 & 0.966 & 0.967 & 0.721 & 0.678 & 0.366 \\
\hline Sequence & 0.704 & 0.968 & 0.758 & 0.831 & 0.407 & 0.431 & 0.994 & 0.876 & 0.620 \\
\hline Subjects & $<0.01$ & 0.663 & $<0.01$ & $<0.01$ & 0.067 & 0.074 & $<0.01$ & $<0.01$ & 0.099 \\
\hline
\end{tabular}

Table 3: $p$-values for sources of variations obtained from Analysis of Variance (ANOVA).

lowest concentration on the calibration curve $(0.02 \mu \mathrm{g} / \mathrm{ml})$ for which an acceptable accuracy of $105.3 \%$ and a precision of $5.97 \%$ were obtained, while the minimum detectable quantity of esomeprazole was found to be $0.01 \mu \mathrm{g} / \mathrm{ml}$. The accuracy was in the range of $95.63 \%$ to $105.34 \%$. The intraday precision (expressed as the \% CV for QC samples of $0.02,0.2$, $2.0 \mu \mathrm{g} / \mathrm{ml}$ ) was in the range of $2.48 \%$ to $8.26 \%$ and inter-day precision was $2.62 \%$ to $17.06 \%$. The recovery of esomeprazole from serum was $96.5 \%$ while that for pantoprazole was $97.3 \%$ and the samples were stable after 6 hours at $25^{\circ} \mathrm{C}$, after 1 day storage at $-80^{\circ} \mathrm{C}$ and after 3 freeze-thaw cycles.

\section{Tolerability}

Both the formulations were well-tolerated. All the 24 volunteers completed the study without any incidence of adverse effects. No clinically significant abnormalities on physical examination including vital signs measurement and ECG recordings and laboratory results were observed.

\section{Pharmacokinetic properties}

The pharmacokinetic parameters of esomeprazole are summarized in Table 1. The Mean (SD) $\mathrm{C}_{\max }$ for test and reference formulations are $1.45(0.53) \mu \mathrm{g} / \mathrm{mL}$ and $1.53(0.47) \mu \mathrm{g} / \mathrm{mL}$, respectively, were attained at mean $\mathrm{T}_{\max }$ of 2.25 and 2.21 hours respectively. All subjects presented an $\mathrm{AUC}_{0-\mathrm{t}} / \mathrm{AUC}_{0-\infty}$ ratio was greater than $80 \%$. The mean elimination half-life was 2.24 and 2.16 hours for test and reference formulations respectively. Mean serum drug concentrations of esomeprazole for both the test and reference formulations are presented in Figure 1.

\section{Statistical analysis}

The pharmacokinetic parameters were tested by paired $t$-test at $5 \%$ level of significance and the values are presented in Table 2 . It can be observed that all the $p$-values are greater than 0.05 indicating no significant difference among the parameters obtained for test and reference formulations.

Analysis of variance (ANOVA) for crossover design was used to assess the effect of formulations, periods, sequences, and subjects on pharmacokinetic parameters [17]. Sequence effect was tested against the between subject mean squares. All other effects were tested against the within subject mean error. No significant formulation, period or sequence effect was observed $(p>0.05)$ for any of the pharmacokinetic parameters (Table 3). But in case of subject variation, significant differences were observed for $\mathrm{C}_{\max }, \mathrm{AUC}_{0-12}, \mathrm{AUC}_{0-\infty}, \mathrm{AUMC}_{0-12}$ and $\mathrm{AUMC}_{0-\infty}$ which are usual due to inter-individual variations among subjects. Since, all of the tested pharmacokinetic parameters indicate the rate and extent of absorption of the administered drug from its

\begin{tabular}{|l|c|c|c|}
\hline & \multicolumn{3}{|c|}{$90 \%$ Confidence Intervals (Cls) } \\
\hline \multicolumn{1}{|c|}{ Parameters } & Point estimate & Upper limit & Lower limit \\
\hline $\mathrm{C}_{\max }$ & 92.56 & 99.93 & 85.73 \\
\hline $\mathrm{AUC}_{0-12}$ & 102.51 & 119.27 & 88.10 \\
\hline AUC $_{0-\infty}$ & 101.92 & 118.96 & 87.32 \\
\hline
\end{tabular}

Table 4: 90\% Confidence Intervals for different pharmacokinetic parameters. dosage form; the insignificant differences between two formulations reflect the therapeutic equivalency of two formulations, test and reference.

The $90 \%$ CI for esomeprazole $\mathrm{C}_{\max }, \mathrm{AUC}_{0-12}$ and $\mathrm{AUC}_{0-\infty}$ were $85.73 \%$ to $99.93 \%, 88.10 \%$ to $119.27 \%$ and $87.32 \%$ to $118.96 \%$, respectively. All the values of the parameters were within the predetermined range of $80 \%$ to $125 \%$ according to the FDA requirement for bioequivalence (Table 4) [10].

\section{Discussions}

To exclude any clinically important differences in the rate and extent at which the active entity of the drugs becomes available at the site of action, assessment of bioequivalence of local product to reference product is necessary. The current study had some limitations that should be considered. This was an open-label study, so it might not address objectively the efficacy and safety profiles of the formulations tested. The study was also limited by inclusion of healthy male volunteers who were administered a single dose in the fasted state, the results cannot be extrapolated to a clinical setting. In the present study, food was strictly controlled and all subjects received the same standardized meal in two periods, thereby minimizing the effect of food consumption. These results remain to be tested for effect of food as well as in patients groups of various ages.

Our study examined the pharmacokinetic properties and bioequivalence of two formulations of esomeprazole capsules in healthy Bangladeshi male volunteers. The pharmacokinetic parameters calculated for both the test and reference formulations were not significantly different, which reflects the comparable pharmacokinetic characteristics of two formulations. All the $90 \%$ confidence intervals for important pharmacokinetics parameters were well within the FDA accepted limits for bioequivalent products $(80-125 \%)$. Both the formulations were well-tolerated and all the 24 volunteers completed the study without any incidence of adverse effects. So it can be concluded that the two formulations are bioequivalent in terms of rate and extent of absorption and hence interchangeable.

\section{References}

1. Hassan-Alin M, Andersson T, Bredberg E, Röhss K (2000) Pharmacokinetics of esomeprazole after oral and intravenous administration of single and repeated doses to healthy subjects. Eur J Clin Pharmacol 56: 665-670.

2. FDA Guidance for Industry (2003) Bioavailability and bioequivalence studies for orally administered drug products. Rockville, MD: Office of Generic Drugs, Division of Bioequivalence, US Food and Drug Administration [cited July 30 2010].

3. Jones B, Kenward GM (2003) Design and analysis of cross-over trials. $2^{\text {n }}$ edition. Champman and Hall/CRC.

4. Nahar K, Joti JJ, Ullah MA, Hasan A, Azad MAK, et al. (2009) A simple RPHPLC method for the determination of omeprazole in human serum and urine: validation and application in pharmacokinetic study. Dhaka Univ J Pharm Sc 8: $123-130$.

5. Portoles A, Terleira A, Almeida S, García-Arenillas M, Caturla MC et al. (2004) Bioequivalence study of two formulations of enalapril, at a single oral dose of $20 \mathrm{mg}$ (tablets): A randomized, two-way, open label, crossover study in healthy volunteers. Curr Ther Res Clin Exp 65: 34-46. 
Citation: Islam MS, Akter N, Shohag H, Ullah A, Al Maruf A, et al. (2011) Bioequivalence Evaluation of Two Esomeprazole 20 mg Capsule Formulations in Healthy Male Bangladeshi Volunteers. J Bioequiv Availab 3: 139-143. doi:10.4172/jbb.1000074

6. McKeage K, Blick SKA Croxtall JD, Lyseng-Williamson KA, Gillian M, et al. (2008) Esomeprazole: a review of its use in the management of gastric acidrelated diseases in adults. Drugs 68: 1571-1607.

7. European Agency for the Evaluation of Medicinal Products, International Conference on Harmonization - World Health Organization Guideline for Good Clinical Practice (2002) ICH topic E6 (R1) [cited July 30, 2010].

8. World Medical Association Declaration of Helsinki (2008) Ethical Principles for Medical Research Involving Human Subjects. Adopted by the $18^{\text {th }}$ WMA General Assembly, Helsinki, Finland, June 1964, and amended by the $59^{\text {th }}$ WMA General Assembly, Seoul, South Korea [cited July 30, 2010].

9. Zeneca A (2010) Nexium (esomeprazole magnesium) prescribing information: delayed-release capsules and delayed-release oral suspension.

10. Andersson T, Hassan-Alin M, Hasselgren G, Röhss K, Weidolf L (2001) Pharmacokinetic studies with esomeprazole, the (S)-isomer of omeprazole. Clin Pharmacokinet. 40: 411-426.

11. Ullah MA, Azad MAK, Sultana R, Akbor MM, Hasan A, et al. (2008) Bioequivalence evaluation of two capsule formulations of amoxicillin in healthy adult male Bangladeshi volunteers: a single-dose, randomized, open-label, two-period crossover study. Curr Ther Res Clin Exp 69: 504-513.
12. Kahrilas PJ, Falk GW, Johnson DA, Schmitt C, Collins DW, et al. (2000) Esomeprazole improves healing and symptom resolution as compared with omeprazole in reflux oesophagitis patients: a randomised controlled trial. Aliment Pharmacol Ther 14: 1249-58.

13. Chow SC, Wang H (2001) On sample size calculation in bioequivalence trials. J Pharmaco-kinet Pharmacodyn 28: 155-169.

14. Äbelö A, Andersson TB, Antonsson M, Naudot AK, Skånberg I, et al. (2000) Stereoselective metabolism of omeprazole by human cytochrome P450 enzymes. Drug Metab Dispos 28: 966-972.

15. Ullah MA, Dowla SU, Maruf AA, Sultana R, Azad MAK, et al. (2010) Pharmacokinetics, Bioequivalence and Tolerability Study of Two Differen Enteric Formulations of Esomeprazole in Healthy Bangladeshi Male Volunteers: An Open Label, Single-Dose, Randomized, Two-Way Crossover Study. Clinical Therapeutics 32: 1419-1426.

16. Scott LJ, Dunn CJ, Mallarkey G, Sharpe M (2002) Esomeprazole: a review of its use in the management of acid-related disorders. Drug 62: 1503-1538.

17. Richter JE, Kahrilas PJ, Johanson J, Maton P, Breiter JR, et al. (2001) Efficacy and safety of esomeprazole compared with omeprazole in GERD patients with erosive esophagitis: a randomized controlled trial. Am J Gastroenterol 96: 656665 